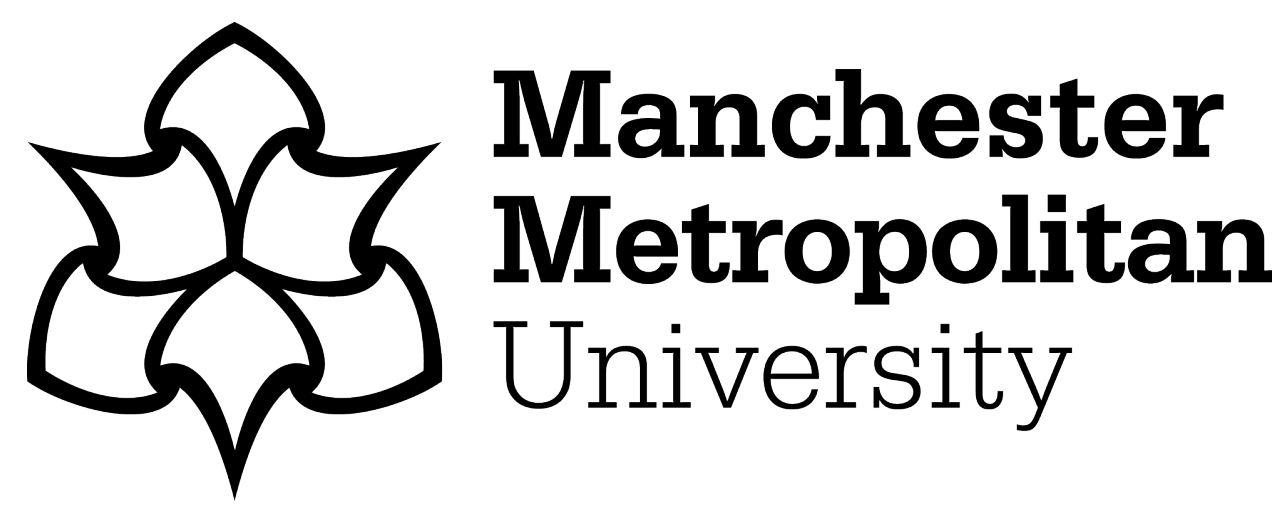

Grubb, Amanda, Joanisse, Sophie ORCID logoORCID: https://orcid.org/0000-0001-9983-9401, Moore, Daniel R, Bellamy, Leeann M, Mitchell, Cameron J, Phillips, Stuart M and Parise, Gianni (2013) IGF-1 colocalizes with muscle satellite cells following acute exercise in humans. Applied Physiology, Nutrition, and Metabolism, 39 (4). pp. 514-518. ISSN 1715-5312

Downloaded from: https://e-space.mmu.ac.uk/626492/

Version: Accepted Version

Publisher: Canadian Science Publishing

DOI: https://doi.org/10.1139/apnm-2013-0430

Please cite the published version 


\title{
IGF-1 colocalizes with muscle satellite cells following acute exercise in humans
}

\author{
Amanda Grubb, Sophie Joanisse, Daniel R. Moore, Leeann M. Bellamy, Cameron J. Mitchell, \\ Stuart M. Phillips, and Gianni Parise
}

\begin{abstract}
Insulin-like growth factor-1 (IGF-1) regulates stem cell proliferation and differentiation in vitro. The aim of this study was to quantify the change in satellite cell (SC) specific IGF-1 colocalization following exercise. We observed a significant increase $(p<0.05)$ in the percentage of SC with IGF-1 colocalization from baseline to $72 \mathrm{~h}$ after a bout of resistance exercise. This strongly supports a role for IGF-1 in human SC function following exercise.
\end{abstract}

Key words: Pax7, IGF-1, acute exercise.

Résumé : Le facteur de croissance insulinomimétique (IGF-1) régule la prolifération et la différenciation des cellules souches in vitro. Cette étude se propose de quantifier la modification à la suite d'un exercice de la colocalisation de l'IGF-1 spécifique aux cellules souches (SC). Nous observons une augmentation significative $(p<0,05)$ du pourcentage de SC en présence de colocalisation de l'IGF-1, et ce, du début à la $72^{\mathrm{e}} \mathrm{h}$ suivant une séance d'exercice contre résistance. Ce phénomène appuie la thèse selon laquelle l'IGF-1 joue un rôle dans la fonction des SC humaines à la suite d'un exercice physique. [Traduit par la Rédaction]

Mots-clés : Pax7, IGF-1, séance d'exercice.

\section{Introduction}

Muscle satellite cells (SC) are monopotent stem cells that represent between $2 \%-4 \%$ of all myonuclei. They are normally quiescent but become activated in response to appropriate cues and aid in muscle growth and repair (Kadi and Thornell 2000; Adams et al. 2002; Petrella et al. 2006). The progression of a SC from quiescence through proliferation and into terminal differentiation is orchestrated by a network of transcription factors known as the myogenic regulatory factors (MRFs) (Rudnicki et al. 2008; Ten Broek et al. 2010); however, many of the upstream cues driving this process remain unknown or poorly understood.

Insulin-like growth factor 1 (IGF-1) is a well-known regulator of muscle development. A role for IGF-1 in muscle growth is supported by reports demonstrating significant muscle hypertrophy in transgenic mice overexpressing IGF-1 (Musaro et al. 2001). Additionally, work in our laboratory implicated local IGF-1 as a regulatory factor in SC activity in humans (McKay et al. 2008).

Alternative spicing of IGF-1 results in 3 distinct splice variants IGF-1Ea, IGF-1Eb, and mechano growth factor (MGF). In vitro, C2C12 myoblasts exposed to MGF or IGF-1Ea proliferate and show impaired differentiation with MGF but not with exposure to IGF-1Ea (Yang and Goldspink 2002). Our work supports this concept, because we report a strong temporal relationship between IGF-1Ea and the mRNA abundance of a driver of differentiation MRF4 (McKay et al. 2008). In contrast, MGF expression was strongly correlated to Myf5 expression, a MRF known for its role in driving proliferation (McKay et al. 2008).
We previously demonstrated qualitative increases in IGF-1 colocalization with SCs following an acute bout of damaging exercise (McKay et al. 2008). The purpose of the current study was to quantify the extent of IGF-1 colocalization with the SC post exercise in a fibre-type specific manner. We hypothesized that following an acute bout of exercise there would be an increase in the colocalization of IGF-1 with SC.

\section{Materials and methods}

Subjects

The study was approved by the Hamilton Health Sciences and McMaster University Faculty of Health Sciences Research Ethics Board. Informed written consent was obtained from all participants prior to the start of the study. Twenty-three healthy, untrained males (18-35 yrs) completed 16 weeks of progressive, whole-body resistance training. All participants were recreationally active and had not participated in a formal weight training program within the 12 months prior to commencement of the study.

\section{Exercise training}

The subjects participated in 4 supervised resistance workouts per week, which consisted of 2 upper and 2 lower body sessions. The training program was designed to progress from 2 sets of each exercise at $70 \%$ of the subject's 1 repetition maximum (RM), to 4 sets at $85 \%$ of 1 RM by the end of the 16 weeks. The last set of each exercise was performed until failure. At the end of each workout, all participants consumed a beverage that contained $30 \mathrm{~g}$ of whey protein to maximize gains in muscle (Cermak et al. 2012). As

Received 23 September 2013. Accepted 19 December 2013.

A. Grubb,* S. Joanisse, ${ }^{*}$ L.M. Bellamy, C.J. Mitchell, and S.M. Phillips. Department of Kinesiology, McMaster University, Hamilton, ON L8S 4L8, Canada. D.R. Moore. Department of Kinesiology, McMaster University, Hamilton, ON L8S 4L8, Canada; Faculty of Kinesiology and Physical Education, University of Toronto, Toronto, ON M5S 2W6, Canada.

G. Parise. ' Department of Kinesiology, McMaster University, Hamilton, ON L8S 4L8, Canada; Department of Medical Physics and Applied Radiation Sciences, McMaster University, Hamilton, ON L8S 4L8, Canada.

Corresponding author: Gianni Parise (e-mail: pariseg@mcmaster.ca).

*Denotes that these authors contributed equally to this manuscript.

†All editorial decisions for this paper were made by Joris Hoeks and Terry Graham. 
Table 1. qRT-PCR primer sequences.

\begin{tabular}{|c|c|c|}
\hline Gene & Forward sequence & Reverse sequence \\
\hline$\beta 2 \mathrm{M}$ & 5'-ATGAGTATGCCTGCCGTGTGA-3' & 5'-GGCATCTTCAAACCTCCATG-3' \\
\hline IGF-1Ea & 5'-GACATGCCCAAGACCCAGAAGGA-3' & 5'-CGGTGGCATGTCACTCTTCACTC-3' \\
\hline IGF-1Eb & 5'-GCССССАТСТАССАACAAGAACAC-3' & 5'-CAGACTTGCTTCTGTCCССТССТTC-3' \\
\hline MGF & 5'-GCCСССАТCTACCAACAAGAACAC-3' & 5'-CGGTGGCATGTCACTCTTCACTC-3' \\
\hline
\end{tabular}

Note: $\beta 2 \mathrm{M}$, beta-2-microglobulin; IGF-1, insulin-like growth factor-1; MGF, mechano growth factor.

described in Mitchell et al. (2013), supplementation was provided to maximize gains in muscle mass and strength; exercise training led to increases in strength and in the muscle fibre cross-sectional area of type I and II fibres.

\section{Acute exercise protocol}

All participants completed 4 sets of 8 repetitions at $80 \%$ of $1 \mathrm{RM}$ pre- and post-training. The exercises included leg press, leg extension, calf press, and leg curl.

\section{Sample collection}

Three muscle biopsies were taken as part of an acute time course before training commenced (baseline, $24 \mathrm{~h}$, and $72 \mathrm{~h}$ after exercise) from the vastus lateralis muscle under local anesthetic (1\% Lidocaine) using a Bergstrom needle adapted for manual suction. Additionally, 3 muscle biopsies were taken as part of an acute time course after 16 weeks of resistance training. Immunofluorescent and gene expression analysis revealed no differences between pre- and post-training acute responses. Therefore analysis was restricted to the pre-training acute time course to assess acute changes following exercise; and to pre- and post-training baseline biopsies to assess a training effect.

\section{Immunofluorescence}

Briefly, sections were fixed in $4 \%$ paraformaldehyde washed several times in phosphate buffered saline with tween, blocked for 90 min then incubated in Pax7 primary antibody (neat, DSHB, Iowa City, Iowa, USA) and myosin heavy chain type II (MHCII; fast isoform; 1:1000; ab91506, Abcam, Cambridge, Mass., USA) at room temperature for $2 \mathrm{~h}$. Sections were washed and incubated in secondary antibody (AlexaFluor 594 goat antimouse; 1:500, and Alexa Fluor 647, 1:500, Invitrogen, Molecular Probes Inc., Grand Island, $\mathrm{NY}$, USA) for $1.5 \mathrm{~h}$ at room temperature. IGF-1 immunofluorescent staining was completed on the same sections as previously described (McKay et al. 2008).

\section{Immunofluorescence data analysis}

Each Pax7 positive nuclei was quantified based on its association to a fibre positive for MHCII staining (type II fibre) or negative for MHCII staining (type I fibre). To determine the proportion of SCs positive for IGF-1, all Pax7 positive nuclei were identified and SCs colocalized with IGF-1 were determined. A SC was considered to be colocalized with IGF-1 when staining of Pax7 and IGF-1 and DAPI overlapped. The quantification of IGF-1 colocalization with SC was conducted on an average of 174 fibres (55 type I and 119 type II) per subject per timepoint.

\section{RNA isolation and quantitative polymerase chain reaction (PCR)}

RNA was isolated from 15-25 mg of muscle using the TrizolRNeasy method as previously reported (Joanisse et al. 2013) RNA integrity reported via RNA integrity numbers (RIN, scale of $0-10$ ) were determined with the Agilent 2100 Bioanalyzer (Agilent Technologies, Toronto, Ont., Canada) on a subset of samples, the average RIN value was 8.2. Samples were reverse transcribed using the commercially available high capacity cDNA reverse transcription kit (Applied Biosystems, Foster City, Calif., USA) in $20 \mu 1$ reaction volumes, as per manufacturer's instructions, using an Eppendorf Mastercycler epgradient thermal cycler (Eppendorf, Mississauga,
Ont., Canada) to obtain cDNA for gene expression analysis. Relative mRNA expression was calculated using the $\Delta \Delta \mathrm{Ct}$ method $\left(2^{-\Delta \Delta C t}\right)$, expression was normalized to housekeeping gene beta-2microglobulin. mRNA values are expressed as fold change from baseline before training (McKay et al. 2008). Primer sequences and target genes are shown in Table 1.

\section{Statistical analysis}

Statistical analysis was performed using SigmaStat 3.1.0 analysis software (Systat Software Inc., Chicago, Ill., USA). One-way repeated-measures ANOVA tests were performed to determine differences in the acute exercise response. Paired $t$ tests were performed to assess the training response for both mRNA and immunofluorescence. To determine specific mean differences a Tukey's HSD post hoc test was used. Statistical significance was considered to be $p<0.05$ with data reported at mean \pm standard error of the mean (SEM).

\section{Results}

\section{Pax7 and IGF-1 colocalization}

IGF-1 colocalization with Pax7 was determined via immunofluorescent staining of muscle cross sections. Figure 1A shows a representative image of the IGF-1-Pax7 staining. Fibre-type specific immunofluorescent staining for IGF-1 and Pax7 demonstrated a significant increase in colocalization of IGF-1 and Pax7 by $72 \mathrm{~h}$ after a single bout of resistance exercise for type I (pre: $6 \pm 3 \%$ SCs positive for IGF-1; post $72 \mathrm{~h}: 20 \pm 5 \%$ SCs positive for IGF-1; $p<0.05$ ) and type II (pre: $8 \pm 2 \%$ SCs positive for IGF-1; post $72 \mathrm{~h}: 26 \pm 5 \%$ SCs positive for IGF-1; $p<0.05$ ). Both type I and type II fibre associated satellite cells were similarly affected by the exercise (Fig. 1D and 1E). No difference in baseline colocalization was seen in either fibre type as a result of training (Fig. $1 \mathrm{~B}$ and $1 \mathrm{C}$ ).

\section{IGF-1 mRNA}

No significant changes were observed after exercise in any IGF-1 splice variants (Fig. 2B). When comparing baseline mRNA before and after training, only IGF-1Ea showed a significant increase in gene expression following 16 weeks of progressive resistance exercise training (Fig. 2A) $(p<0.05)$.

\section{Discussion}

We previously reported significant correlations between IGF-1 splice variants and MRF gene expression following an acute bout of muscle damaging exercise, inferring a role for IGF-1 in the regulation of SC. Furthermore, we identified, that SC were considered to be colocalized with IGF-1 following damaging exercise providing further support that IGF-1 plays a role in human SC activity (McKay et al. 2008). The present results extend on our initial findings by demonstrating for the first time in human muscle that the proportion of SC considered to be colocalized with IGF-1 increases after an acute bout of exercise.

Consistent with our previous preliminary observations, we observed a significant increase in IGF-1 colocalization with SC $72 \mathrm{~h}$ post exercise. It is interesting, however, that no fibre-type difference in the extent of IGF-1 colocalization with SC was observed. Both type I and type II associated SC colocalized with IGF-1 increased $72 \mathrm{~h}$ post exercise. Additionally, the extent of IGF-1 was considered to be colocalized with SC was not different before 
Fig. 1. (A) Representative image (merge) of IGF-1, Pax7, MHCII, and DAPI immunofluorescent stain. The yellow arrow denotes a type 2 fibreassociated satellite cell positive for IGF-1, whereas the white arrow denotes a type 1 fibre-associated satellite cell negative for IGF-1. Single channel views of (a) Pax7 (red), (b) IGF-1 (green), and (c) DAPI (blue) are provided along with a combined image of (d) Pax7 and IGF-1. No differences were observed in the colocalization of IGF-1 and SC at baseline before and after training in (B) type 1 fibres and (C) type 2 fibres. Significant increases $(p<0.05)$ in the percentage of SC colocalized with IGF-1 were seen $72 \mathrm{~h}$ after exercise in an acute post-exercise time course in both (D) type 1 and (E) type 2 fibres.
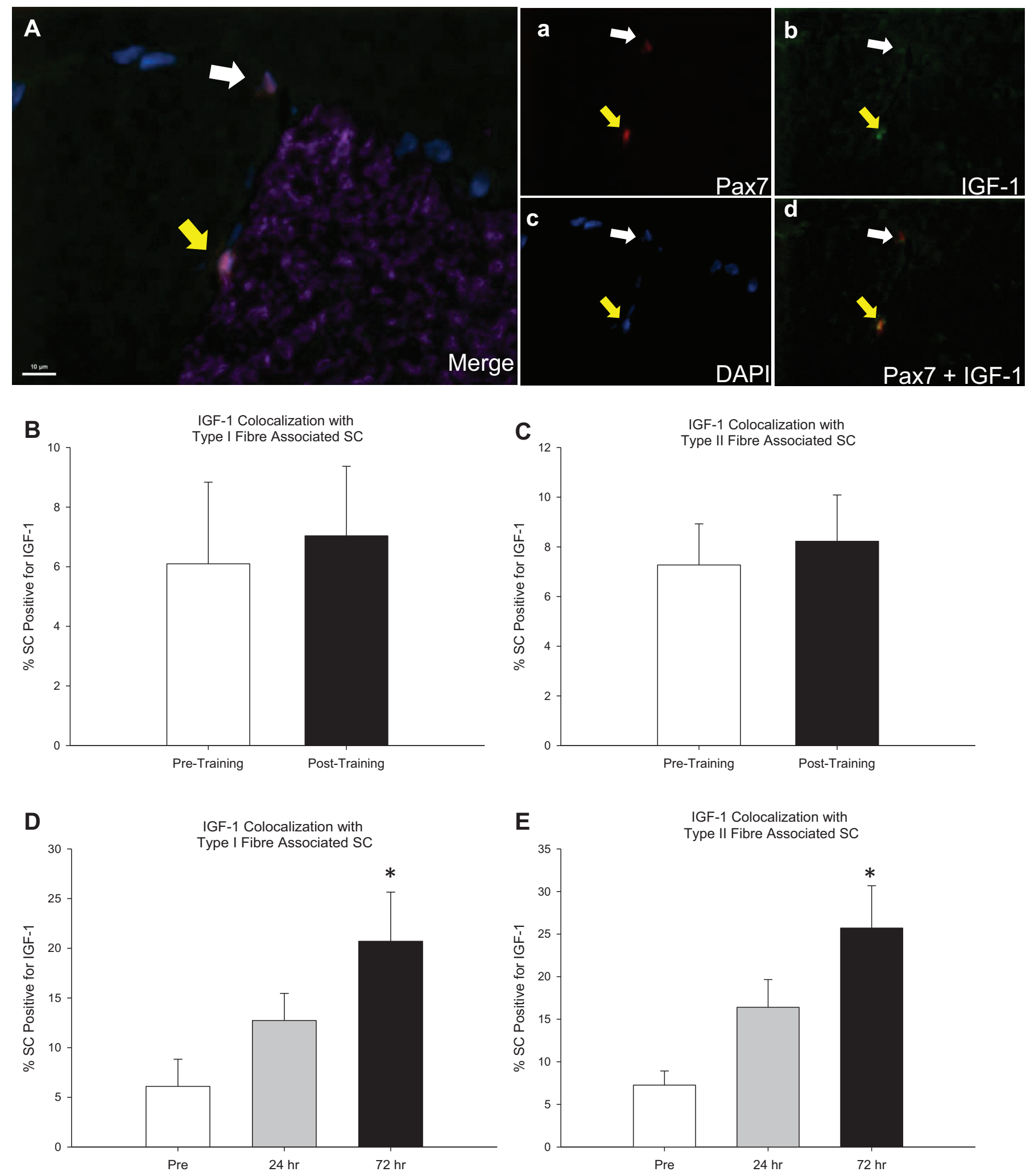
Fig. 2. Whole-muscle mRNA of IGF-1Ea, IGF-1Eb, and MGF was quantified (A) acutely after an exercise bout and (B) at baseline before and after training. * indicates a significant change $(p<0.05)$ compared with baseline measures.

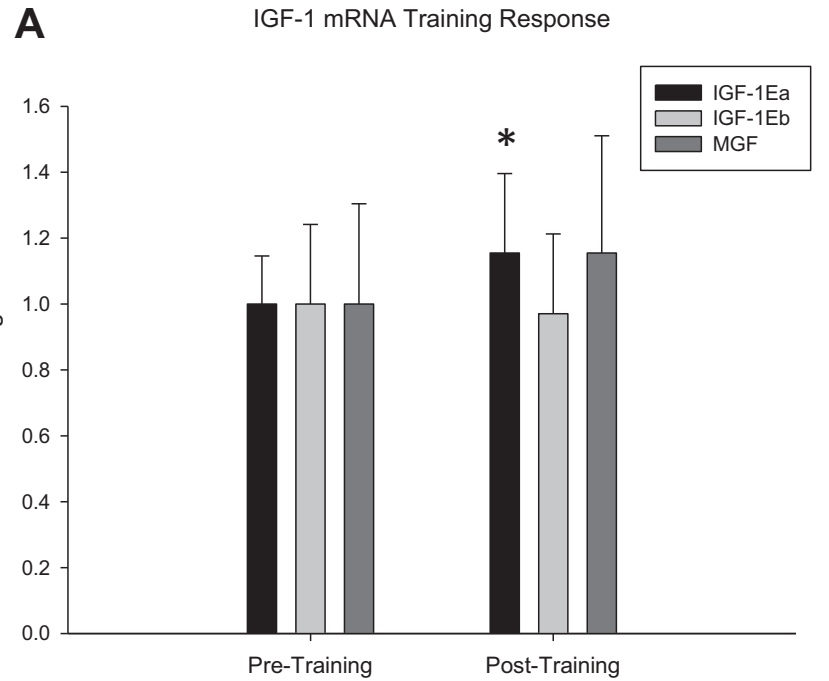

and after training. This suggests that the extent to which IGF-1 is considered to be colocalized with SC is a conserved response and is independent of training status and fibre type.

The demonstrated increase in IGF-1 associated with SC provides evidence of a role for IGF-1 in SC activity in vivo. Because MGF has been suggested to be involved in SC proliferation (Yang and Goldspink 2002; McKay et al. 2008), it is conceivable that the increase in SC-specific IGF-1 contributes to the expansion of the SC pool following exercise. The later rise in IGF-1Ea may stimulate the progression of SC through the myogenic program towards differentiation (Hill and Goldspink 2003; McKay et al. 2008).

Unfortunately, commercially available antibodies against specific IGF-1 splice variants are not currently available and preclude our ability to provide further insight as to which splice variants are colocalizing with $\mathrm{SC}$ at various post exercise time points. The current study demonstrates a progressive increase in the number of SC colocalized with IGF-1 from baseline to $72 \mathrm{~h}$ post exercise. Based on our results we suggest that IGF-1 likely plays a role in SC function following acute exercise. Given the timing of the observed response it is likely that IGF-1 is involved in the progression of SC through the myogenic program from proliferation through to differentiation.

Changes in whole-muscle IGF-1 mRNA expression following damaging exercise have been well described (Hameed et al. 2003; Greig et al. 2006; McKay et al. 2008). Surprisingly, no change in IGF-1 gene expression was observed in the acute time course following exercise. This could be attributed to the fact that the stimulus in the current study was of a lower intensity and volume than used in previous investigations (Hameed et al. 2003; Greig et al. 2006; McKay et al. 2008). The specific intensity and volume used in this investigation was to reflect a more typical resistance exercise bout. Importantly, it is worth noting that we observed a significant increase in IGF-1Ea gene expression following training compared with pre-training baseline levels.

This is the first study to quantify SC-specific colocalization of IGF-1 and how it is impacted by acute exercise and exercise training. Although the exercise stimulus was not intense enough to detect a change in whole-muscle mRNA levels of IGF-1 splice variants acutely following exercise, it was enough to induce a significant increase in IGF-1 colocalization with SC. The increase in SC-specific IGF-1 colocalization suggests that local production of
B IGF-1 mRNA Acute Timecourse

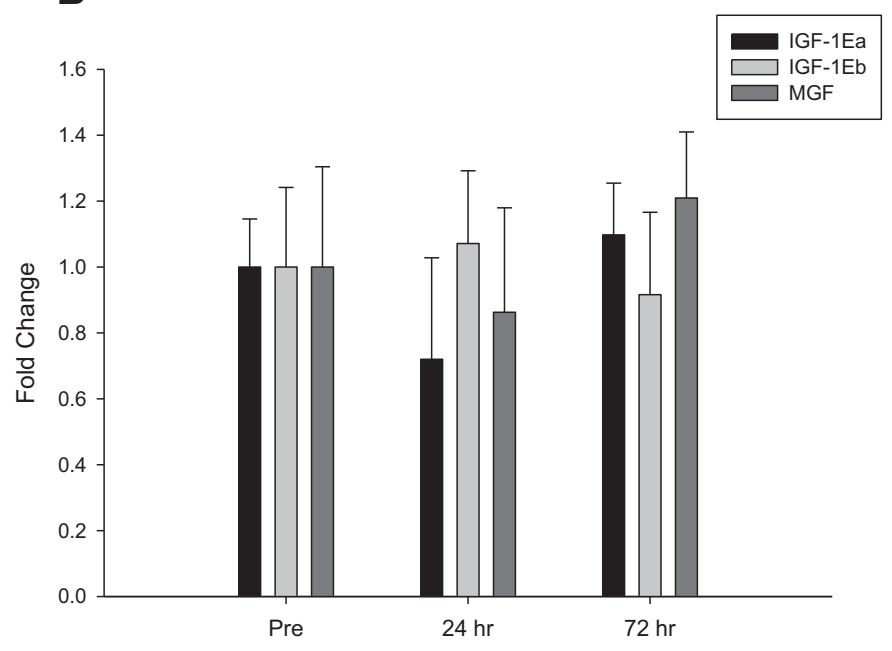

IGF-1 may be part of the normal post-exercise SC response and appears to be independent of training status and fibre type.

\section{Acknowledgements}

The Pax7 hybridoma cells developed by Dr. A. Kawakarri, were obtained from the Developmental Studies Hybridoma Bank (DSHB) developed under the auspices of the NICHD and maintained by the University of Iowa, Department of Biology, Iowa City, IA52242 USA.

\section{References}

Adams, G.R., Caiozzo, V.J., Haddad, F., and Baldwin, K.M. 2002. Cellular and molecular responses to increased skeletal muscle loading after irradiation. Am. J. Physiol. Cell Physiol. 283(4): C1182-C1195. doi:10.1152/ajpcell.00173.2002. PMID:12225982.

Cermak, N.M., Res, P.T., de Groot, L.C., Saris, W.H., and van Loon, L.J. 2012. Protein supplementation augments the adaptive response of skeletal muscle to resistance-type exercise training: a meta-analysis. Am. J. Clin. Nutr. 96(6): 1454-1464. doi:10.3945/ajcn.112.037556. PMID:23134885.

Greig, C.A., Hameed, M., Young, A., Goldspink, G., and Noble, B. 2006. Skeletal muscle IGF-I isoform expression in healthy women after isometric exercise. Growth Horm. IGF Res. 16(5-6): 373-376. doi:10.1016/j.ghir.2006.09.005. PMID: 17107821.

-Hameed, M., Orrell, R.W., Cobbold, M., Goldspink, G., and Harridge, S.D. 2003. Expression of IGF-I splice variants in young and old human skeletal muscle after high resistance exercise. J. Physiol. 547(1): 247-254. doi:10.1113/jphysiol. 2002.032136. PMID:12562960.

Hill, M., and Goldspink, G. 2003. Expression and splicing of the insulin-like growth factor gene in rodent muscle is associated with muscle satellite (stem) cell activation following local tissue damage. J. Physiol. 549(2): 409-418. doi:10.1113/jphysiol.2002.035832. PMID:12692175.

Joanisse, S., Gillen, J.B., Bellamy, L.M., McKay, B.R., Tarnopolsky, M.A., Gibala, M.J., and Parise, G. 2013. Evidence for the contribution of muscle stem cells to nonhypertrophic skeletal muscle remodeling in humans. FASEB. J. 27(11): 4596-4605. doi:10.1096/fj.13-229799. PMID:23928822.

Kadi, F., and Thornell, L.E. 2000. Concomitant increases in myonuclear and satellite cell content in female trapezius muscle following strength training. Histochem. Cell Biol. 113(2): 99-103. doi:10.1007/s004180050012. PMID:10766262.

McKay, B.R., O'Reilly, C.E., Phillips, S.M., Tarnopolsky, M.A., and Parise, G. 2008. Co-expression of IGF-1 family members with myogenic regulatory factors following acute damaging muscle-lengthening contractions in humans. J. Physiol. 586(22): 5549-5560. doi:10.1113/jphysiol.2008.160176. PMID:18818249.

Mitchell, C.J., Churchward-Venne, T.A., Bellamy, L., Parise, G., Baker, S.K., and Phillips, S.M. 2013. Muscular and systemic correlates of resistance traininginduced muscle hypertrophy. PLoS One, 8(10): e78636. doi:10.1371/journal. pone.0078636. PMID:24130904.

Musaro, A., McCullagh, K., Paul, A., Houghton, L., Dobrowolny, G., Molinaro, M., et al. 2001. Localized Igf-1 transgene expression sustains hypertrophy and regeneration in senescent skeletal muscle. Nat. Genet. 27(2): 195-200. doi:10. 1038/84839. PMID:11175789.

Petrella, J.K., Kim, J., Cross, J.M., Kosek, D.J., and Bamman, M.M. 2006. Effi- 
cacy of myonuclear addition may explain differential myofiber growth among resistance-trained young and older men and women. Am. J. Physiol. Endocrinol. Metab. 291(5): E937-E946. doi:10.1152/ajpendo.00190. 2006. PMID:16772322.

Rudnicki, M.A., Le Grand, F., McKinnell, I., and Kuang, S. 2008. The molecular regulation of muscle stem cell function. Cold Spring Harb. Symp. Quant. Biol. 73: 323-331. doi:10.1101/sqb.2008.73.064. PMID:19329572.
Ten Broek, R.W., Grefte, S., and Von den Hoff, J.W. 2010. Regulatory factors and cell populations involved in skeletal muscle regeneration. J. Cell. Physiol. 224(1): 7-16. doi:10.1002/jcp.22127. PMID:20232319.

Yang, S.Y., and Goldspink, G. 2002. Different roles of the IGF-1 Ec peptide (MGF) and mature IGF-1 in myoblast proliferation and differentiation. FEBS Lett. 522(1-3): 156-160. doi:10.1016/S0014-5793(02)02918-6. PMID:12095637. 